\title{
Differential Gene Expression During Conidiation in the Grape Powdery Mildew Pathogen, Erysiphe necator
}

\author{
Laura Wakefield, David M. Gadoury, Robert C. Seem, Michael G. Milgroom, Qi Sun, and Lance Cadle-Davidson
}

First, second, third, and sixth authors: Department of Plant Pathology and Plant-Microbe Biology, Cornell University, Geneva, NY 14456; fourth author: Department of Plant Pathology and Plant-Microbe Biology, and fifth author: Computational Biology Service Unit, Cornell University, Ithaca, NY 14853; and sixth author: United States Department of Agriculture-Agricultural Research Services, Grape Genetics Research Unit, 630 W. North St., Geneva, NY 14456.

Accepted for publication 4 March 2011.

\begin{abstract}
Wakefield, L., Gadoury, D. M., Seem, R. C., Milgroom, M. G., Sun, Q., and Cadle-Davidson, L. 2011. Differential gene expression during conidiation in the grape powdery mildew pathogen, Erysiphe necator. Phytopathology 101:839-846.

Asexual sporulation (conidiation) is coordinately regulated in the grape powdery mildew pathogen Erysiphe necator but nothing is known about its genetic regulation. We hypothesized that genes required for conidiation in other fungi would be upregulated at conidiophore initiation or full conidiation (relative to preconidiation vegetative growth and development of mature ascocarps), and that the obligate biotrophic lifestyle of E. necator would necessitate some novel gene regulation. cDNA amplified fragment length polymorphism analysis with 45 selective primer combinations produced $\approx 1,600$ transcript-derived fragments (TDFs), of which 620 (39\%) showed differential expression. TDF

expressed, annotated sequences had similarity to fungal genes of unknown function. The remaining genes had annotated function in metabolism, signaling, transcription, transport, and protein fate. As expected, a portion of orthologs known in other fungi to be involved in developmental regulation was upregulated immediately prior to or during conidiation; particularly noteworthy were several genes associated with the light-dependent VeA regulatory system, G-protein signaling (Pth11 and a kelch repeat), and nuclear transport (importin- $\beta$ and Ran). This work represents the first investigation into differential gene expression during morphogenesis in E. necator and identifies candidate genes and hypotheses for characterization in powdery mildews. Our results indicate that, although control of conidiation in powdery mildews may share some basic elements with established systems, there are significant points of divergence as well, perhaps due, in part, to the obligate biotrophic lifestyle of powdery mildews.
\end{abstract} sequences were annotated using BLAST analysis of GenBank and of a reference transcriptome for E. necator developed by 454-FLX pyrosequencing of a normalized cDNA library. One-fourth of the differentially
Additional keywords: expression analysis, Uncinula.
In powdery mildews, rapid production of asexual conidia enables dispersal and expansion of population size, while sexual ascocarps are required for survival of abiotic stresses and of host dormancy in the absence of living green tissues. For Erysiphe necator (syn. Uncinula necator), the causal agent of grapevine powdery mildew, the developmental cues for conidiation are dependent on a number of factors, including inoculum density, light, temperature, and humidity $(12,15,32,41)$. In spite of the gradient in age across a colony, E. necator conidiation occurs synchronously at a defined and predictable time, suggesting the presence of a signal to coordinate conidiation (41). Further evidence of the coordinate regulation of conidiation in E. necator occurs after pairing of opposite mating types and ascocarp formation, when conidial production ceases (20).

Corresponding author: L. Cadle-Davidson;

E-mail address: Lance.CadleDavidson@ars.usda.gov

Mention of trade names or commercial products is solely for the purpose of providing specific information and does not imply recommendation or endorsement by the United States Department of Agriculture (USDA). USDA is an equal opportunity provider and employer.

* The $\boldsymbol{e}$-Xtra logo stands for "electronic extra" and indicates that the online version contains one supplemental table.

doi:10.1094/PHYTO-11-10-0295

This article is in the public domain and not copyrightable. It may be freely reprinted with customary crediting of the source. The American Phytopathological Society, 2011
To date, however, no work has been done to uncover the genetic basis for developmental signals or how these signals might control powdery mildew development in general. In contrast, significant progress has been accomplished with several other fungi $(13,19,21,22)$, including a major effort in the model fungus Aspergillus nidulans to elucidate regulatory genes and signaling pathways for developmental control $(10,18,21,44)$. Functional analyses have uncovered roles for several transcription factors, including the $\mathrm{C} 2 \mathrm{H} 2$ transcription factors $\operatorname{brlA}, \mathrm{FlbC}$, and SteA $(2,27,41)$, a single Myb transcription factor $F l b D(42)$, and $a b a A$ and $w e t A$, which, along with $\operatorname{brlA}$, form a central regulatory pathway for conidiation (1). These and other pathway regulators activate 1,200 conidiation-specific genes (38). For example, abaA coordinates regulation of a number of structural genes, including the chitin synthases $\operatorname{chs} A$ and $\operatorname{chs} C$; the $\triangle \operatorname{chs} A \Delta \operatorname{chs} C$ double mutant mimics the aberrant conidiophore morphology of mutants defective in $a b a A$ or $b r l A$ (24). In powdery mildews, many of these transcription factors and structural genes could be involved in the developmental commitment to conidiation.

A significant barrier to expression analyses in powdery mildews has been the paucity of publicly available gene sequences, with the notable exception of Blumeria graminis. Outside of the phylogenetically distinct tribe of powdery mildews that contains only B. graminis (7), only 23 expressed sequence tags have been deposited at GenBank for the Erysiphales to date (28). This lack of expression data is partially due to the inability to maintain the fungus in the absence of the host. However, recent advances have enabled the isolation of high-quality E. necator RNA without contaminating host RNA (9). Still, without sequence data, approaches 
to gene expression analysis are limited to open-platform technologies that discover gene sequences. The cDNA amplified fragment length polymorphism (AFLP) technique allows the simultaneous comparison of expression of uncharacterized genes across multiple treatments or developmental stages, the discovery of new gene sequences, and higher stringency than other differential-display methods, thus reducing some potential for false positives (4).

The goal of the present research was to identify gene sequences differentially expressed during vegetative growth and throughout asexual and sexual reproduction in E. necator. Previously, we have used microsurgery to restart the E. necator developmental clock by excising the colony center precisely before conidiation (20). By sequentially excising the centers of colonies that were (i) at a presporulation stage or (ii) sporulation competent, we were able to define precisely when a purported sporulation signal might be propagated within the colony. With this detailed knowledge of the timing of signal initiation for conidiation, we were able here to study expression precisely before conidiation signaling (preconidiation), afterward at conidiophore initiation and full conidiation, and during ascocarp development when conidiation is again halted. We hypothesized that homologs of genes required for conidiation in other fungi would be upregulated at conidiophore initiation or full conidiation, and that the obligate biotrophic lifestyle and synchronous conidiation of $E$. necator would necessitate some novel gene regulation.

\section{MATERIALS AND METHODS}

Plant material, inoculum, and pathogen growth. Seedlings were grown from seed collected from susceptible open-pollinated Vitis vinifera vines according to Ficke et al. (17). The seedlings were grown in constant $23^{\circ} \mathrm{C}$ with a 12 -h photoperiod until the five- to six-leaf stage under mildew-free conditions. Two isolates of E. necator, 10-18 and 10-36, of opposite mating type were collected from New York vineyards and maintained on seedlings under the same conditions. For growth of the asexual stages, conidia were harvested from colonies $\approx 8$ days postinoculation (dpi) by shaking infected leaves in distilled water containing $0.005 \%$ Tween 20 . The suspensions were adjusted to a concentration of $40,000 / \mathrm{ml}$ by counting with a hemacytometer, and inoculated as described below. For colonies where sexual reproduction was desired, conidial suspensions of both isolates were prepared as above, mixed in equal proportion, and vortexed to create one suspension of both mating types.

Colonies for RNA extraction were prepared by placing two dozen 5- $\mu$ l drops of the conidial suspension (200 conidia/drop) across the surface of the youngest fully expanded leaf of a grape seedling. The suspension was allowed to dry and then the seedlings were placed in a mildew-free growth chamber at $23^{\circ} \mathrm{C}$ with a 12-h photoperiod. When the colonies reached the desired stage, all inoculated leaves were observed under a dissecting microscope for uniformity of development. Mildew colonies showing at least $90 \%$ uniformity in terms of relative radial growth of colonies and appearance of the appropriate conidiation stage

TABLE 1. Forty-five selective nucleotide primer combinations used in the cDNA amplified fragment length polymorphism analysis of differential expression across four developmental time points in Erysiphe necator

\begin{tabular}{ll}
\hline TaqI +2 & \multicolumn{1}{c}{ AseI+2 } \\
\hline CA & GA, GG, GT \\
CC & AG, GA, GT \\
CG & GA, GG, GT \\
CT & GA, GG, GT \\
GA & AG, GA, GC, GG, GT, TG \\
GC & AA, AG, CC, GA, GC, GG, GT, TG \\
GG & AA, AG, GA, GC, GG, GT, TG \\
GT & AG, CC, CT, GA, GC, GG, GT, TA \\
TG & GA, GC, GG, GT \\
\hline
\end{tabular}

(i.e., for colonies in the conidiophore development stage, $>90 \%$ of colonies on selected leaves showed conidiophore emergence but no fully developed conidia) were selected for RNA extraction.

RNA isolation. RNA was extracted from powdery mildew colonies at each of four stages: preconidiation (3 dpi), conidiophore initiation $(\approx 5 \mathrm{dpi})$, full conidiation ( $8 \mathrm{dpi}$ ), and development of mature ascocarps $(\approx 4$ weeks post inoculation). All RNA extractions were performed according to Cadle-Davidson et al. (9). For the three asexual stages, two independent isolations were performed from each of two isolates. For the sexual stage, four independent isolations were performed of the same pair of isolates. Within each stage, equal amounts of total RNA were pooled from the four independent extractions to form one pool per stage of interest. Polyadenylated mRNA was isolated from total RNA using the PolyATtract system (Promega Corp., Madison, WI). The mRNA was not eluted from the beads in the final step, and the beads were used directly in the iScript cDNA Synthesis Kit (BioRad, Hercules, CA) to convert the mRNA into cDNA.

cDNA-AFLP analysis. The cDNA-AFLP protocol was adapted from Bachem et al. (4), using the same adapters and primers described therein. cDNA from each stage was digested with TaqI followed by AseI digestion. The digested fragments were then ligated to TaqI and AseI adapters prior to preamplification with Taq $\mathrm{I}+0$ and $A s e \mathrm{I}+0$ primers. Amplification conditions were as follows: 4 min of denaturation at $94^{\circ} \mathrm{C}$ and then 27 cycles of $30 \mathrm{~s}$ of denaturation at $94^{\circ} \mathrm{C}, 30 \mathrm{~s}$ of annealing at $55^{\circ} \mathrm{C}$, and $60 \mathrm{~s}$ of extension at $72^{\circ} \mathrm{C}$. After preamplification, products were diluted to $1 \mathrm{ng} / \mu \mathrm{l}$ (approximately fivefold dilution).

Diluted preamplification product $(5 \mu \mathrm{l})$ was used as template for selective amplifications. Selective amplification was carried out with 45 primer combinations using two selective nucleotides for each primer (e.g., TaqI+2 and AseI+2) for the selective nucleotide combinations listed in Table 1 . The polymerase chain reaction (PCR) amplification program was as follows: denaturation at $94^{\circ} \mathrm{C}$ for $4 \mathrm{~min}$; then 13 cycles of denaturation at $94^{\circ} \mathrm{C}$ for $30 \mathrm{~s}$, annealing at $65^{\circ} \mathrm{C}$ for $30 \mathrm{~s}$ (reduced $0.7^{\circ} \mathrm{C}$ per cycle), and extension at $72^{\circ} \mathrm{C}$ for $60 \mathrm{~s}$; followed by 32 cycles of $30 \mathrm{~s}$ of denaturation at $94^{\circ} \mathrm{C}, 30 \mathrm{~s}$ of annealing at $56^{\circ} \mathrm{C}$, and $60 \mathrm{~s}$ of extension at $72^{\circ} \mathrm{C}$.

Selective amplification products were separated by electrophoresis on a $5 \%$ polyacrylamide gel in a Bio-Rad Protean II xi Gel System at $40 \mathrm{~W}$ and $45^{\circ} \mathrm{C}$ for $3.5 \mathrm{~h}$. Following separation, fragments were visualized by silver staining according to the protocol by Echt et al. (16). Fragments of interest were picked from the gel using a sterile pipette tip, transferred to $100 \mu \mathrm{l}$ of distilled water in a microcentrifuge tube, and heated to $95^{\circ} \mathrm{C}$ for $10 \mathrm{~min}$. This eluted DNA $(1 \mu \mathrm{l})$ was used as a template for reamplification using the preamplification primers under the following conditions: 4 min of denaturation at $94^{\circ} \mathrm{C}$; followed by 8 cycles of $30 \mathrm{~s}$ of denaturation at $94^{\circ} \mathrm{C}, 30 \mathrm{~s}$ of annealing at $61^{\circ} \mathrm{C}$ (reduced by $0.7^{\circ} \mathrm{C}$ per cycle), and $60 \mathrm{~s}$ of extension at $72^{\circ} \mathrm{C}$; followed by 24 cycles of $30 \mathrm{~s}$ of denaturation at $94^{\circ} \mathrm{C}, 30 \mathrm{~s}$ of annealing at $56^{\circ} \mathrm{C}$, and $60 \mathrm{~s}$ of extension at $72^{\circ} \mathrm{C}$. PCR samples $(15 \mu \mathrm{l})$ were electrophoresed in a $1 \%$ agarose gel and visualized using UV excitation of SYBR Green in the loading dye. PCR products with visible, single bands were purified using Sephadex columns and Sanger sequenced directly using each preamplification primer at Cornell University's Core Laboratories Center (CLC).

Normalized cDNA library and 454 pyrosequencing. $E$. necator isolate G14 was collected from a no-spray plot of the Vitis interspecific hybrid Rosette in an experimental vineyard in Geneva, NY, in September 2007. RNA was isolated from cultures of G14 according to Cadle-Davidson et al. (9) at 17 dpi and provided to Bio S\&T (Montreal, CA) for preparation of an uncloned normalized cDNA library for 454 pyrosequencing and a cloned library for quality assessment. A sodium chloride precipitation was completed at Bio S\&T prior to library construction due 
to a low 260/230 ratio. Purified cDNAs were digested after normalization with $S f i$ I for directional cloning. After purification, the digested cDNA fragments were ligated into pBluescriptII SK(-) with SfiI A\&B inserts between EcoRI and XhoI. A portion of the ligation products was transformed into DH10B-T1R (Invitrogen, Carlsbad, CA). Ten colonies were arbitrarily selected from the cloned library and insert sizes were determined by PCR using M13 primers.

Pyrosequencing by a 454-FLX (454 Life Sciences, Branford, CT) was completed at Cornell CLC. After in silico removal of adaptor sequences from the raw sequencing reads for the $5^{\prime}$ end (5'-CAGTGGTATCAACGCAGAGTGGCCATTACGGCCT AGTTACGGG-3' and the $3^{\prime}$ end (5'-[PolyA]GGCCGCCTCGGC CACTCTGCGTTGATACCACTG-3'), MIRA software (14) was used to assemble the reads into contigs de novo.

Sequence analysis. Similarity searching by blastx and tblastx was carried out against the National Center for Biotechnology Information (NCBI) nonredundant (nr) BLAST database. To increase the probability of finding a match, longer sequences corresponding to the amplified cDNA-AFLP products were found by performing a nucleotide BLAST (blastn) of each sequence against the normalized cDNA database described above. cDNA contigs matched in this search were then searched as six-frame translations against the translated NCBI nr database using tblastx.

Real-time PCR confirmation. To confirm differential expression of the identified sequences, quantitative reverse-transcription (qRT)-PCR) was performed using a MyiQ thermal cycler (BioRad), $1.5 \mu \mathrm{M}$ Syto 9 for product quantification (Invitrogen), and $10 \mathrm{nM}$ fluorescein (Sigma-Aldrich, St. Louis) for well factor normalization. For preliminary assessment of the isolate-independent differential expression of genes, colonies were grown from two isolates of E. necator, Fcon2 and G9. Fcon2 was collected in September 2007 from an abandoned Concord vineyard in Fredonia, NY. G9 was collected in June 2007 from the same no-spray Rosette vineyard as G14. RNA was isolated from colonies of Fcon 2 at preconidiation, conidiophore initiation, and full conidiation and from paired Fcon2 and G9 at ascocarp initiation. These stages were identical to those used within the cDNA-AFLP experiments, with the exception of the sexually reproducing stage, wherein RNA was isolated from colonies at ascocarp initiation rather than maturation. For the qRT-PCR experiments, only one RNA isolation was performed per stage of interest as opposed to the four used in the cDNA-AFLP analysis. Extraction of the RNA, purification of mRNA, and synthesis of cDNA were performed as described above. Each sample was then normalized to equalize cDNA concentration. Following purification, the cDNA samples and remaining mRNA were analyzed with $E$. necator primers to confirm the absence of E. necator genomic DNA.

After analyzing the sequence data from the cDNA-AFLP experiment, 17 sequences with a match in the BLAST searches were arbitrarily selected. Primers for real-time PCR were designed for all 17 sequences and tested for quantitative response to gDNA and specificity by melt curve analysis. Following this initial analysis, seven sequences were selected for further analysis based on a linear response of threshold cycle $(\mathrm{Ct})$ to logtransformed starting quantity and a single sharp peak at the amplicon's melting temperature in the dissociation, or melt curve, analysis. In addition to normalization based on cDNA concentration, an amplification control, histone H3, previously shown to be evenly expressed throughout $B$. graminis f. sp. hordei development (6), was included in all qRT-PCR experiments. Three technical qRT-PCR replicates were performed for all samples. The PCR amplification program was as follows for all qRT-PCR experiments: $10 \mathrm{~min}$ of denaturation at $95^{\circ} \mathrm{C}$; followed by 45 cycles of $15 \mathrm{~s}$ of denaturation at $95^{\circ} \mathrm{C}, 45 \mathrm{~s}$ of annealing at $58^{\circ} \mathrm{C}$, and $60 \mathrm{~s}$ of extension at $72^{\circ} \mathrm{C}$; this was followed by a melt curve analysis ramping from 55 to $95^{\circ} \mathrm{C}$ in 15 -s increments of $0.4^{\circ} \mathrm{C}$. Normalized relative quantity (NRQ) values were calculated as described elsewhere (34) to compare a single cDNAAFLP upregulated developmental stage relative with background expression in the other stages, normalized by expression of the control gene histone H3 (6). NRQ values $>1$ reflect higher expression at the expected developmental stage.

\section{RESULTS}

cDNA-AFLP sequences. In total, 45 primer combinations were used for cDNA-AFLP analysis, each resulting in 21 to 64 transcript-derived fragments (TDFs) in a size range of $\approx 100$ to $800 \mathrm{bp}$ (Fig. 1). Across all 45 primer combinations, $\approx 1,600$ TDFs

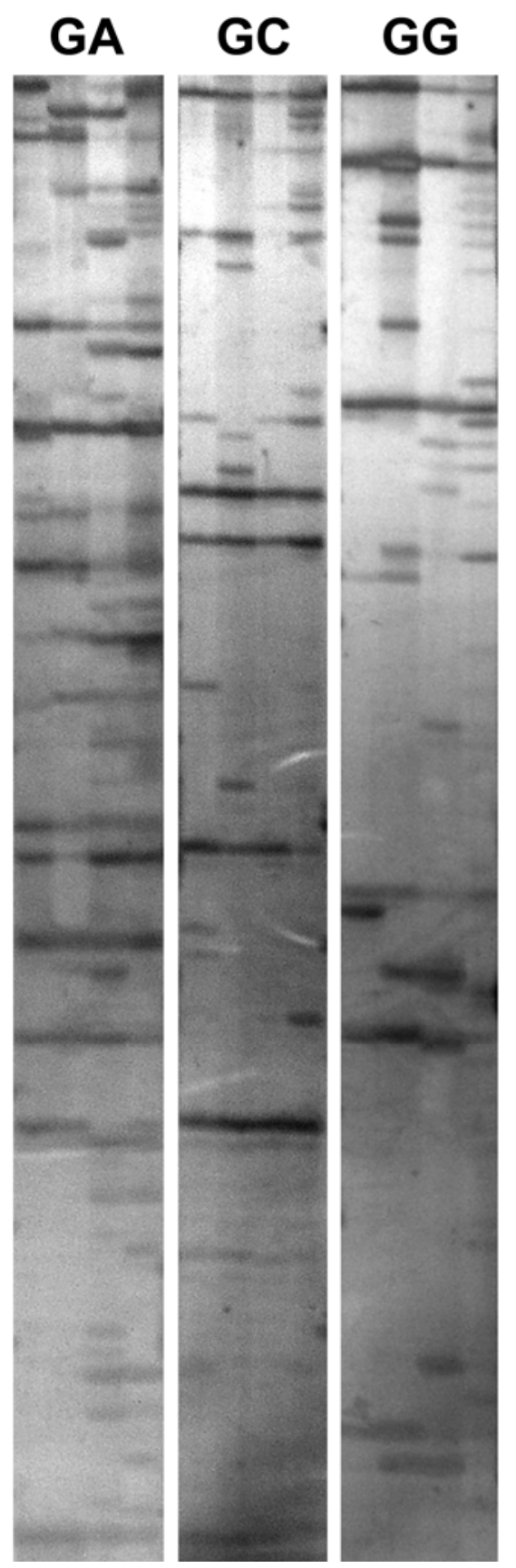

Fig. 1. Representation of differential expression of Erysiphe necator transcripts across four developmental stages for three cDNA amplified fragment length polymorphism primer combinations. Transcript profiles are shown for three AseI+2 primers (GA, GC, and GG) with the AG TaqI+2 primer. cDNA pools within each gel from left to right are column 1, preconidiation; column 2 , conidiophore initiation; column 3 , full conidiation; and column 4 , ascocarp maturation. These three gels show a molecular weight range of $\approx 100$ to $800 \mathrm{bp}$. 
were visualized. Within these, 620 TDFs (39\%) were polymorphic among the four stages, suggesting differential expression. Of these polymorphic TDFs, 230 were directly sequenced (Supplemental Table 1). The remaining 390 fragments (out of the $620 \mathrm{TDFs}$ ) either gave poor product upon reamplification or gave a degraded product when sequenced, likely due to co-migration of different sequences. When searched against the GenBank database using tblastx, 45 of the 230 sequences $(20 \%)$ had a significant match ( $E$ value $\leq 1 \mathrm{E}-03$ ) (Table 2$)$. Only one sequence matched the $V$. vinifera genome, indicating that the extraction method was successful in targeting $E$. necator RNA.
Pyrosequence matches. To improve the ability to find matches, a reference transcriptome for E. necator was developed by 454-FLX pyrosequencing of a normalized cDNA library of isolate G14. The average insert size of this library was $2.3 \mathrm{~kb}$ (Fig. 2). However, after one sequencing run, insufficient coverage resulted in an average contig size of only $591 \mathrm{bp}$ (Table 3). The TDFs were searched against this E. necator cDNA sequence database using blastn. Of the 230 sequences searched against the library, $153(67 \%)$ showed significant matches to cDNA contigs. The 153 matching contigs were searched against the GenBank database, again using tblastx, and $116(76 \%)$ had a significant

TABLE 2. Annotation of select transcript-derived fragments (TDFs) identified by cDNA amplified fragment length polymorphism as differentially regulated during Erysiphe necator development

\begin{tabular}{|c|c|c|c|c|c|}
\hline Primers $^{\mathrm{a}}$ & Fragment ID & Stage $^{c}$ & $E$ value cDNA $^{\mathrm{d}}$ & Annotation ${ }^{\mathrm{e}}$ & $E$ value GenBank ${ }^{\mathrm{f}}$ \\
\hline \multicolumn{6}{|c|}{ Metabolism } \\
\hline CA-GA & $9-13-28$ & 3 & $6 \mathrm{E}-27$ & Lysine synthesis/Lys2 (XP_002143711) & $9 \mathrm{E}-132$ \\
\hline CC-GA & $11-13-11$ & 1 & 3 E-92 & Spermine/spermidine synthase (EEH21650) & $1 \mathrm{E}-136$ \\
\hline GA-GG & $13-16-17$ & 1 & 5 E-37 & Acetolactase synthase (XP_962652) & 0 \\
\hline GA-GG & $13-16-18$ & $1-3$ & 5 E-34 & Pap2 domain protein (XP_001931173) & $1 \mathrm{E}-72$ \\
\hline TG-GT & $8-14-12$ & $1-3$ & 7 E-29 & Cytochrome P450 (XP_755288) & $1 \mathrm{E}-60$ \\
\hline GT-GG & $14-16-19$ & $1-3$ & 4 E-34 & Vacuolar ATP synthase subunit B (XP_001557622) & 0 \\
\hline GG-AG & $16-4-7$ & $2-4$ & 1 E-66 & Protoheme IX farnesyl transferase (EER45220) & $3 \mathrm{E}-72$ \\
\hline GG-GC & $16-15-11$ & $3-4$ & $1 \mathrm{E}-47$ & Alcohol dehydrogenase (EEH49979) & $8 \mathrm{E}-47$ \\
\hline TG-GT & $8-14-11$ & $1-3$ & $6 \mathrm{E}-54$ & Actin polymerization protein/Bzz1 (XP_749256) & $5 \mathrm{E}-87$ \\
\hline GG-GG & $16-16-21$ & $1-3$ & $3 \mathrm{E}-23$ & Fatty aldehyde dehydrogenase (XP_001932922) & $3 \mathrm{E}-165$ \\
\hline GG-AG & $16-4-3$ & 1,4 & $4 \mathrm{E}-40$ & Caleosin domain protein (XP_001932418) & $2 \mathrm{E}-53$ \\
\hline TG-GA & $8-13-22$ & 1 & $2 \mathrm{E}-39$ & Elongation factor 3 (XP_001593480) & 0 \\
\hline GT-GT & $14-14-15$ & 4 & $2 \mathrm{E}-56$ & $\gamma$ Tubulin (XP_001903940) & $6 \mathrm{E}-76$ \\
\hline GT-GT & $14-14-11$ & $2-4$ & 7 E-65 & Gal4-like transcriptional activator (AAG25917) & $4 \mathrm{E}-117$ \\
\hline GC-GT & $15-14-31$ & 2 & 5 E-6 & Transcriptional activator Spt7 (EEHO4734) & $3 \mathrm{E}-51$ \\
\hline GG-GG & $16-16-7$ & $2-4$ & 3 E-38 & Transcriptional elongation factor Spt6 (EEH34974) & 0 \\
\hline GG-AG & $16-4-2$ & 1,4 & $3 \mathrm{E}-56$ & FlbD (EEd33126) & $1 \mathrm{E}-4$ \\
\hline GG-TG & $16-8-9$ & $2-3$ & 4 E-32 & Ring finger domain protein (XP_00125767) & 7 E-130 \\
\hline GC-GA & $15-13-10$ & $1-3$ & $2 \mathrm{E}-41$ & CobW domain protein (XP_002384953) & $3 \mathrm{E}-170$ \\
\hline GT-TT & $14-6-8$ & $2-4$ & $5 \mathrm{E}-47$ & Mads box transcription factor (XP_001935687) & 7 E-46 \\
\hline GC-GG & $15-16-10$ & $1-3$ & $6 \mathrm{E}-51$ & Histone transcriptional regulator (CAE85596) & $2 \mathrm{E}-34$ \\
\hline CA-GA & $9-13-17$ & 4 & 3 E-9 & PHD and ring finger domain protein (EER42091) & 1 E-43 \\
\hline \multicolumn{6}{|c|}{ 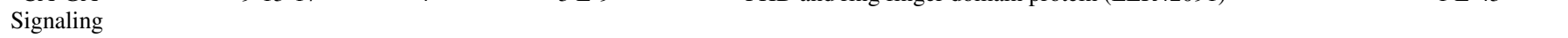 } \\
\hline TG-GA & $8-13-19$ & $1-2$ & $4 \mathrm{E}-50$ & Calcium permease (XP_001547054) & $1 \mathrm{E}-73$ \\
\hline GA-GA & $13-13-3$ & 2 & $1 \mathrm{E}-179$ & Integral membrane protein/Pth11 homolog (AAD30437) & $6 \mathrm{E}-64$ \\
\hline CA-GA & $9-13-24$ & 4 & $2 \mathrm{E}-24$ & Catalase peroxidase (Q8X1N3) & 0 \\
\hline CA-GT & $9-14-35$ & 3 & $3 \mathrm{E}-38$ & Cystolic regulator Pianissimo (XP_001938513) & 0 \\
\hline GT-TG & $16-8-8$ & 1,4 & 3 E-64 & PRELI/MSF1 domain protein (EER25643) & $2 \mathrm{E}-57$ \\
\hline GT-TA & $14-5-1$ & 1 & * & MFS monocarboxylic acid transporters (EDP52060) & $5 \mathrm{E}-07$ \\
\hline \multicolumn{6}{|c|}{ 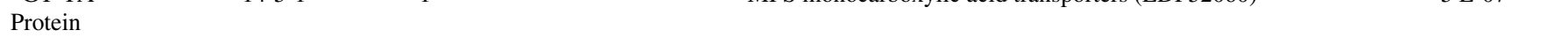 } \\
\hline TG-GA & $8-13-21$ & 3 & 7 E-46 & ER-associated proteolytic system protein DER1 (XP_747611) & $3 \mathrm{E}-77$ \\
\hline TG-GT & $8-14-21$ & 2 & 9 E-39 & Heat shock protein 70 (EU311400) & 0 \\
\hline GA-GG & $13-16-9$ & 3 & $2 \mathrm{E}-58$ & F Box domain protein (XP_001272021) & $2 \mathrm{E}-105$ \\
\hline
\end{tabular}

a Primer combinations are given by selective nucleotides in the following $5^{\prime}-3^{\prime}$ format: AseI primer-TaqI primer. Transcription = transcription factors/DNA binding, Transport $=$ transport/cell membrane proteins, and Protein $=$ protein maintenance and degradation .

${ }^{\mathrm{b}}$ Each TDF fragment was given a number based on the primers used (first two numbers) and the fragment number within each primer combination.

${ }^{\mathrm{c}}$ Stages of expression are represented as follows: $1=$ preconidiation, $2=$ conidiophore initiation, $3=$ full conidiation, and $4=$ development of mature ascocarps.

d TDFs with no match to the Erysiphe necator cDNA pyrosequences are scored with a * in the blastn search against the E. necator cDNA library. The $E$ value given is for the highest match against the cDNA library.

e Tblastx was conducted for each cDNA contig sequence against the GenBank database, and the annotation of the gene with highest similarity is given here. Where no contig was matched, the annotation is given on the direct search of the original TDF against the GenBank database.

${ }^{\mathrm{f}} E$ values of the gene with highest similarity in tblastx are listed for the direct search of the cDNA library contig or TDF sequence against the GenBank database. 
match. Nine of the TDFs without matches in the E. necator transcriptome contigs directly matched the GenBank database, for a total of 125 TDFs (54\%) with sequence similarity high enough by this approach to consider them putative homologs.

Functional classification and confirmation. Five functional classes of differentially expressed fragments were identified: metabolism, transcription, signaling, transport, and protein fate. Based on relevance of the match annotation to previously described conidiation-associated genes, select matches to the GenBank database are listed in Table 2 (a complete list of sequences is available in Supplemental Table 1). In all, 105 of the 230 sequences $(46 \%)$ had no significant match at GenBank by a query of either the TDF or the sequence with highest similarity in the E. necator cDNA database. An additional 33 TDFs (14\%) matched hypothetical fungal protein sequences of unknown function. Among the sequences that matched those of predicted or known function, the largest class, representing $13 \%$ of differential transcripts, was sequences involved in metabolism. qRT-PCR expression analysis was used to test whether differential expression of arbitrarily chosen, annotated genes was dependent on the isolate used. Expression results using RNA from isolate Fcon2 and a pairing of Fcon2 with isolate G9 confirmed expected stages of upregulation based on results for isolates 10-18 and 10-36 from the cDNA-AFLP analysis for seven of nine developmental stages (Table 4).

\section{DISCUSSION}

The cDNA-AFLP method of analyzing gene expression across developmental stages has been described as useful for comparisons across multiple treatments in non-model species $(31,35)$ and particularly appropriate in studies of obligate biotrophs, where tissue and sequence information are limiting (40). Our results with E. necator demonstrated the utility of cDNA-AFLP in morphogenesis studies in this pathosystem. Using 45 primer combinations, we were able to visualize $\approx 620$ differentially expressed fragments out of 1,600 total fragments. Although this level of differential expression is high for this type of study, the result is not surprising, considering the many changes of the fungus from purely vegetative growth to asexual and ultimately sexual reproduction in this study. In addition, developmental events related to host infection occur at the same time.

Several sequences fulfilled expectations of differential expression. Analysis of those sequences that showed similarity to previously described sequences revealed several patterns in gene expression, described by gene category below, with each TDF identified as ("AFLP fragment ID": "stage"), with stage defined as 1 = preconidiation, $2=$ conidiophore initiation, $3=$ full conidiation, and $4=$ ascocarp.
Metabolism. The largest class of identified genes was involved in cell metabolism. A number of the metabolism genes are expressed early on in the vegetative and asexual stages of growth but are switched off in late stages of infection (Table 2), which is not surprising because the fungus transitions from biotrophic colonization and conidiation to ascocarp maturation and dormancy. Structural proteins such as chitin synthase play key roles in conidiation (24), and at least one chitin synthase (15-14-33: $1,2)$ is upregulated in E. necator prior to full conidiation.

Several sequences were similar to genes involved in lipid metabolism, including links to molecules like oxylipins that have demonstrated roles in coordinating fungal development. One TDF showed a relatively strong match to a Pap2 domain protein (13$16-18 ; 1,2,3)$ linked to nutrient stress responses in yeast (22) and to the generation and degradation of lipid-signaling molecules (11). Sporulation in response to nutrient stress is common in filamentous fungi, and the Pap2 domain proteins may be responsible for the coordination of a lipid signal that stimulates this response.

Caleosins are strongly associated with the maintenance of storage lipid bodies in plant seed and fungal spores, and individual members are involved in oxylipin pathways (30). The caleosin domain sequence $(16-4-3: 1,4)$ in E. necator may have a role early in infection to maintain lipid bodies upon which germinating spores rely until successful infection occurs, and again during sexual reproduction to produce storage bodies for the developing ascospores. Because conidiation is an energyintensive process, a developmental program that halts conidiation to preserve host resources would be a distinct advantage.

Signaling. The greatest similarities between E. necator sequences and the model systems were noticed in signaling. In other fungi, heterotrimeric G-protein signaling has a well-established role in coordinating multiple responses, including conidiation (44). We have uncovered several elements of G-protein signaling that indicate that the same basic elements may provide the basis for developmental control in E. necator.

One TDF (13-13-3: 2) showed moderate similarity to homologs of Pth11. Pth11 has been predicted to encode a G-protein-coupled

TABLE 3. Results of 454-FLX pyrosequencing and de novo assembly of an Erysiphe necator normalized cDNA library

\begin{tabular}{lc}
\hline Sequencing results & Values \\
\hline Total sequence & $82 \mathrm{Mb}$ \\
Reads placed in contigs & $99 \%$ \\
Total contigs & 32,405 \\
Contigs $<500 \mathrm{bp}$ & 18,088 \\
Average contig length & $591 \mathrm{bp}$ \\
Range of contig length & $0.05-5.8 \mathrm{~kb}$ \\
Average reads per contig & 9.1 \\
Range of reads per contig & $2-800$ \\
\hline
\end{tabular}



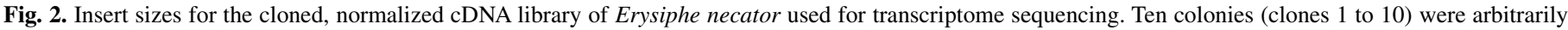

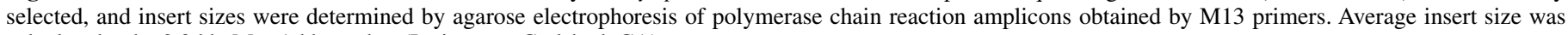
calculated to be $2.3 \mathrm{~kb} . \mathrm{M}=1$-kb marker (Invitrogen, Carlsbad, CA). 
receptor (GPCR) in Magnaporthe oryzae and may play a role in pathogenesis-related morphogenesis (29). Its specific expression at the transient stage of conidiophore initiation makes this gene an interesting candidate as a key signaling receptor immediately prior to conidiation.

In Aspergillus spp., the primary $\mathrm{G} \alpha$ subunit that coordinates asexual development is FadA (36). Peeters et al. (33) demonstrated in yeast that two kelch repeat proteins, Krh1p and Krh2p, can bypass the need for cAMP and directly link G $\alpha$ subunits with protein kinase A. A kelch-repeat sequence in E. necator (9-13-27: 2) (confirmed by qRT-PCR) was expressed coincident with the putative GPCR sequence, thus suggesting that, indeed, it may have some role in transmitting signals received through the GPCR described above. In Dictyostelium spp., Pianissimo (9-14-35: 3) (confirmed by qRT-PCR) is required for the G-protein-linked cAMP signaling.

Transcriptional regulators. The third-largest group of discovered genes consisted of those involved in transcriptional regulation and DNA binding, with upregulation most often at the conidiophore initiation stage (Table 2), indicating large changes in gene regulation at this time point. In Aspergillus spp., flbD encodes a constitutively expressed myb-like DNA-binding protein necessary for early-stage conidiation events (42). A weak match in E. necator (16-4-2: 1,4) was not expressed when expected and likely possesses a different function in E. necator. Several $\mathrm{C} 2 \mathrm{H} 2$ transcription factors have known roles in conidiation (e.g., brlA and $F l b C$ ) or cleistothecial development (e.g., SteA) $(2,27,43)$. We identified three sequences with similarity to $\mathrm{C} 2 \mathrm{H} 2$ transcription factors (14-13-9: 1,2, [confirmed by qRT-PCR] 12-13-8: 1, and 14-4-18: 4), none of which was expressed during conidiation. A more detailed phylogenetic analysis of the matching contigs may provide interesting insight into the conserved or novel roles of these transcription factors.

Cell membrane or transport. In Aspergillus spp., the velvet protein (VeA) complex plays a critical role in controlling asexual versus sexual development, acting in the nucleus to repress asexual development in the dark, and being excluded from the nucleus in light (5). Araújo-Bazán et al. (3) recently demonstrated that importin- $\alpha$ interacts with VeA, and importin- $\alpha$ mutants show impaired nuclear transport of VeA. We have found a sequence showing similarity to the importin- $\beta$ subunit (15-13-14: 1,2), which joins importin- $\alpha$ in a heterodimer required for proper function.

Related to the function of importin is Ran, a small GTPase. The importin heterodimer releases its contents in the nucleus upon disassociation of the heterodimer, stimulated by the interaction of the $\beta$-subunit with Ran (3). A sequence showing similarity to Ran
(8-16-11: 2,3) was expressed slightly later than the importin- $\beta$ subunit. Studies in Exserohilum spp. also showed upregulation of Ran during conidiation and not in earlier stages (19). Nuclear transport may be impaired until initiation of conidiation, with the Ran-importin interaction important for import of complexes that trigger rather than repress conidiation.

Protein maintenance or degradation. Studies in Neurospora spp. have indicated that genes involved in protein degradation are upregulated during asexual sporulation (25). The Cop9 signalosome, which has functions in targeted protein degradation, coordinates development in Aspergillus spp. (8) and plays a role in regulation of PpoA expression (39). F-box proteins, which act as substrate receptors for ubiquitin ligase, have also been proven necessary for proper cell division and sexual spore development in Aspergillus spp. (26).

Among the sequences related to protein degradation, two were specifically upregulated at full conidiation: an $\mathrm{F}$ box domain protein (13-16-9: 3) and a proteolytic system protein (8-13-21: 3), though upregulation of the former was not independently confirmed in isolate Fcon2 (Table 4). Proteolytic systems could be necessary for turnover of protein complexes responsible for the suppression of asexual development. Although no turnover points have yet been discovered, VeA contains PEST domains for rapid turnover, indicating that degradation of VeA is important for development control (10).

Novel sequences in conidiation. Several sequences identified here have not previously been found to be expressed during conidiation in other filamentous fungi and could provide novel inroads to our understanding of conidiation and of E. necator biology. This expectation is exemplified by the most highly upregulated gene in this study, a PRELI/MSF1 domain-containing sequence $(16-8-8: 1,4)$ which is likely involved in intramitochondrial protein sorting (23) but has not previously been implicated in conidiation. Specialization of gene sequences and genetic regulation involved in conidiation could be expected in part due to the obligate biotrophic lifestyle of powdery mildews. Not only are host factors likely to affect fungal development but also the genomes of powdery mildews have undergone massive gene loss and gene shuffling as a result of extreme parasitism (37). In the process, regulatory pathways and structural proteins are likely to have been disrupted and new genes appropriated for the task. This will require functional analysis in powdery mildews to determine gene functions that are out of context in autotrophic fungi.

Technical considerations. Outside of the phylogenetically distinct tribe of powdery mildew fungi that contains only $B$. graminis (7), almost no sequence data have been deposited at

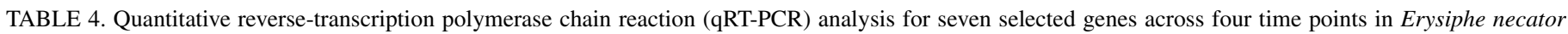
isolate Fcon2

\begin{tabular}{|c|c|c|c|c|c|}
\hline Fragment ID ${ }^{\mathrm{a}}$ & Expected expression $^{\mathrm{b}}$ & $\mathrm{NRQ}^{\mathrm{c}}$ & Annotation & Forward primer $^{\mathrm{d}}$ & Reverse primer ${ }^{d}$ \\
\hline $\mathrm{n} / \mathrm{a}$ & Normalizer gene & 1.0 & Histone $\mathrm{H} 3$ & TAACACGCTTGGCATGGATA & TGGAACAGTTGCTCTTCGTG \\
\hline \multirow[t]{2}{*}{$14-13-9$} & Preconidiation & 1.3 & $\mathrm{C} 2 \mathrm{H} 2$ zinc finger transcription factor & CAACGCCGCAGATACTAAAT & AGCGCCAATTGATAAGACTG \\
\hline & Conidiophore initiation & 1.1 & $\ldots$ & & \\
\hline \multirow[t]{2}{*}{$16-8-8$} & Preconidiation & 11.0 & PRELI/MSF1 domain protein & TGCTCAAGTTTCTCCCTCAC & CTGTTGCGATCGGTAAGTCT \\
\hline & Ascocarp initiation & 140.6 & $\ldots$ & & \\
\hline $9-13-27$ & Conidiophore initiation & 37.8 & Kelch repeat protein & TCAGTCTCCTCCAAGTTTCG & CCTCAACGTAGGCTTTACGA \\
\hline $11-13-20$ & Ascocarp initiation & 1.9 & Acetyl CoA synthetase FacA & GTGATGCGGCAAGTAGAGAT & TCGAGAGATCCAAAGACTGG \\
\hline $9-14-35$ & Full conidiation & 2.1 & Pianissimo & CAGCTGCTTGTTACCCAGTT & CGTCCAAGAAACCAATCATC \\
\hline $13-16-9$ & Full conidiation & 0.1 & F-box domain protein & GAATCGTATGTCGCATTTCC & GTCCAGATTGTCCCACTGAG \\
\hline $9-13-24$ & Ascocarp initiation & 0.3 & Catalase peroxidase & TTCTTGGGGAGGTGAGACAA & GCGACCAAAAGTAACTCGAA \\
\hline
\end{tabular}

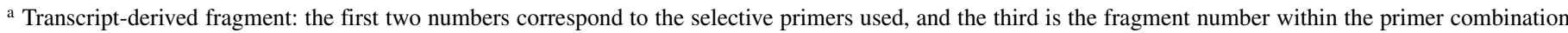

(Table 3 and supplemental Table 1); n/a = not applicable.

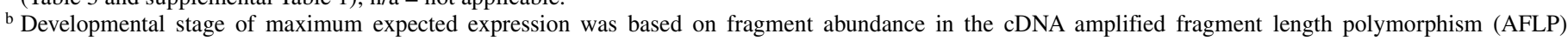
analysis of isolates 10-18 and 10-36. For qRT-PCR, Fcon2 was paired with G9 for ascocarp initiation as an imperfect confirmation of ascocarp maturation from cDNA-AFLP analysis of isolates 10-18 and 10-36.

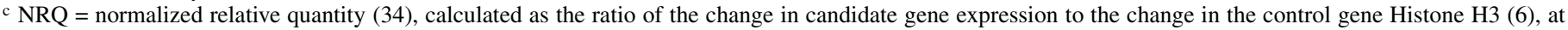
the listed developmental stages. NRQ values $>1$ (highlighted in bold) reflect higher expression at the expected developmental stage.

d Primer sequences used for qRT-PCR. All primers are shown 5'-3'. 
GenBank for the Erysiphales (28). This situation, combined with the short sequences we obtained after amplification and sequencing of TDFs, resulted in only $20 \%$ of TDFs having putative homologs in GenBank. Therefore, we pyrosequenced a normalized cDNA library during a growth stage that had initiated secondary conidial infections. Although our sequencing depth provided contigs (average $591 \mathrm{bp}$ ) that were smaller than the estimated cDNA insert size (2.3 kb) (Table 3; Fig. 2), the cDNA library sequence nearly tripled the number of TDFs that could be functionally annotated. Still, cDNA-AFLP has the limitation of only tracking those transcripts with the restriction sites and selective nucleotides (here, 45 of 256 possible) used and only identifying previously sequenced genes. As a result, we were able to annotate only a fraction of the genes expressed in association with conidiation. Developing the resources for transcriptome expression profiling (e.g., high-throughput sequencing) would enable the discovery of all differentially regulated genes.

For preliminary assessment of the isolate-independent differential expression of genes, colonies were grown from a third isolate of E. necator, Fcon2, and a pairing of Fcon2 with G9 for qRTPCR analysis of candidate genes. We decided to confirm results with additional isolates rather than with isolates 10-18 and 10-36 to estimate how many genes might have conserved roles in morphogenesis, rather than simply confirm the technical and biological reproducibility of cDNA-AFLP and qRT-PCR in this experimental system. For seven of nine of the stages for which increased expression was expected based on cDNA-AFLP, results confirmed expectations (Table 4), suggesting that many genes identified here may be differentially expressed through development independent of the isolate used. Due to technical barriers to obtaining fully mature cleistothecia from the Fcon2-G9 pairing, we replaced the mature ascocarp stage with ascocarp initiation, which may be a different enough developmental stage to have significant transcriptional differences compared with the former. When expression was expected to be highest at full conidiation, high levels of expression were also seen at ascocarp initiation. Gadoury et al. (20) demonstrated that ascocarp formation was temporally associated with cessation of conidial production. Because RNA was extracted at ascocarp initiation for qRT-PCR as opposed to fully mature ascocarps in the cDNA-AFLP work, conidiation had not yet completely shut off and some overlap between expression at full conidiation and this stage was to be expected.

Conclusions. This work represents the first investigation into differential gene expression during morphogenesis in E. necator and identifies candidate genes and hypotheses for further characterization in powdery mildews. Our results reveal that there may be some similarities in control of development between $E$. necator and other fungi. Particularly noteworthy were several genes with similarities to those associated with the lightdependent VeA regulatory system, G-protein signaling, transcriptional regulation, and nuclear transport in A. nidulans. The largest groups of sequences, however, were those with no match to known sequences (45\%) and unknown function (14\%). This indicates that, although control of conidiation in E. necator may share some basic elements with established systems, there are likely significant points of divergence as well, due in part to the extreme parasitic nature of obligate biotrophs. Through this intimate connection with the host plant, powdery mildews may rely on the host for developmental cues in ways autotrophic fungi like Aspergillus and Neurospora spp. do not. Characterization of these novel mechanisms for regulating fungal development will require functional genetic analysis to fully characterize conidiation in obligate biotrophic fungi.

\section{ACKNOWLEDGMENTS}

This research was supported by the United States Department of Agriculture (USDA) Agricultural Research Service Grape Genetics
Research Unit and by grants from the USDA Viticulture Consortium-East, the New York Wine and Grape Foundation, the Kaplan Fund, and Hatch project NYC-153410. We thank M. Brewer for sharing isolates of $E$. necator and C. Galvani for additional sequencing of cDNA-AFLP fragments.

\section{LITERATURE CITED}

1. Adams, T., Wiser, Y. U., and Yu, J.-H. 1998. Asexual sporulation in Aspergillus nidulans. Microbiol. Mol. Biol. Rev. 62:35-54.

2. Adams, T. H., Boylan, M. T., and Timberlake, W. E. 1988. brlA is necessary and sufficient to direct conidiophore development in Aspergillus nidulans. Cell 54:353-362.

3. Aráujo-Bazán, L., Dhingra, S., Chu, J., Fernández-Martínez, J., Calvo, A. M., and Espeso, E. A. 2009. Importin $\alpha$ is an essential nuclear transport carrier required for proper sexual and asexual development and secondary metabolism in Aspergillus nidulans. Fungal Genet. Biol. 46:506-515.

4. Bachem, C. W. B., Van der Hoeven, R. S., de Bruijin, S. M., Vreugdenhil, D., Zabeau, M., and Visser, R. G. F. 1996. Visualization of differential gene expression using a novel method of RNA fingerprinting based on AFLP: Analysis of gene expression during tuber development. Plant J. 9:745-753.

5. Bayram, Ö., Krappmann, S., Ni, M., Bok, J. W., Helmstaedt, K., Valerius, O., Braus-Stromeyer, S., Kwon, N.-J, Keller, N., Yu, J.-H, and Braus, G. 2008. VelB/VeA/LaeA complex coordinates light signal with fungal development and secondary metabolism. Science 320:1504-1506.

6. Both, M., Eckert, S. E., Csukai, M., Muller, E., Dimopoulos, G., and Spanu, P. D. 2005. Transcript profiles of Blumeria graminis development during infection reveal a cluster of genes that are potential virulence determinants. Mol. Plant-Microbe Interact. 18:125-133.

7. Braun, U., Cook, R. T. A., Inman, A. J., and Shin, H.-D. 2002. The taxonomy of the powdery mildew fungi. Pages 13-55 in: The Powdery Mildews: A Comprehensive Treatise. R. R. Belanger, W. R. Bushnell, A. J. Dik, and T. L. W. Carver, eds. American Phytopathological Society Press, St. Paul, MN.

8. Busch, S., Eckert, S., Krappmann, S., and Braus, G. 2003. The COP9 signalosome is an essential regulator of development in the filamentous fungus Aspergillus nidulans. Mol. Microbiol. 49:717-730.

9. Cadle-Davidson, L., Wakefield, L., Seem, R. C., and Gadoury, D. M. 2010. Specific isolation of RNA from the grape powdery mildew pathogen Erysiphe necator, an epiphytic, obligate parasite. J. Phytopathol. 158:69-71.

10. Calvo, A. M. 2008. The VeA regulatory system and its role in morphological and chemical development in fungi. Fungal Genet. Biol. 45:1053-1061.

11. Carman, G. M., and Han, G. S. 2006. Roles of phosphatidate phosphatase enzymes in lipid metabolism. Trends Biochem. Sci. 31:694-699.

12. Carroll, J. E., and Wilcox, W. F. 2003. Effects of humidity on the development of grapevine powdery mildew. Phytopathology 93:11371144.

13. Chen, M. Y., Long, Y., and Devreotes, P. N. 1997. A novel cytosolic regulator, pianissimo, is required for chemoattractant receptor and Gprotein-mediated activation of the 12 transmembrane domain adenylyl cyclase in Dictyostelium. Gene Dev. 11:3218-3231.

14. Chevreux, B., Pfisterer, T., Drescher, B., Driesel, A. J., Muller, W. E. G., Wetter, T., and Suhai, S. 2004. Using the miraEST assembler for reliable and automated mRNA transcript assembly and SNP detection in sequenced ESTs. Genome Res. 14:1147-1159.

15. Delp, C. J. 1954. Effect of temperature and humidity on the grape powdery mildew fungus. Phytopathology 44:615-626.

16. Echt, C. S., May-Marquardt, P., Hseih, M., and Zahorchak, R. 2006. Characterization of microsatellite markers in eastern white pine. Genome 39:1102-1108.

17. Ficke, A., Gadoury, D. M., Seem, R. C., and Dry, I. B. 2003. Effects of ontogenic resistance upon establishment and growth of Uncinula necator on grape berries. Phytopathology 93:556-563.

18. Fischer, R., and U. Kües. 2006. Asexual sporulation in mycelial fungi. Pages 263-292 in: The Mycota I Growth, Differentiation and Sexuality. R. Fischer and U. Kües, eds. Springer-Verlag, Berlin.

19. Flaherty J. E., and Dunkle, L. D. 2004. Identification and expression analysis of regulatory genes induced during conidiation in Exserohilum turcicum. Fungal Genet. Biol. 42:471-481.

20. Gadoury, D. M., Wakefield, L. M., Seem, R. C., Cadle-Davidson, L., and Dry, I. B. 2010. Effect of prior vegetative growth, inoculum density and light on conidiation in Erysiphe necator. Pages 51-53 in: Proc. 6th Int. Workshop on Grapevine Downy and Powdery Mildew. A. Calonnec, F. Delmotte, R. Emmett, D. M. Gadoury, C. Gessler, D. Gubler, H.-H. Kassemeyer, P. A. Magarey, M. Raynal, and R. C. Seem, eds. INRA Bordeaux-Aquitaine, Bordeaux, France. 
21. Garcia-Rico, R. O., Fierro, F., and Martin, J. F. 2008. Heterotrimeric G(alpha) protein Pga1 of Penicillium chrysogenum controls conidiation mainly by a cAMP-independent mechanism. Biochem. Cell Biol. 86:5769.

22. Han, G. S., Johnston, C. N., Chen, X., Athenstaedt, K., Daum, G., and Carman, G. 2001. Regulation of the Saccharomyces cerevisiae DPP1encoded diacylglycerol pyrophosphate phosphatase by zinc. J. Biol. Chem. 276:10126-10133.

23. Huh, W.-K., Falvo, J. V., Gerke, L. C., Carroll, A. S., Howson, R. W., Weissman, J. S., and O'Shea, E. K. 2003. Global analysis of protein localization in budding yeast. Nature 425:686.

24. Ichinomiya, M., Ohta, A., and Horiuchi, H. 2005. Expression of asexual developmental regulator gene $a b a A$ is affected in the double mutants of classes I and II chitin synthase genes, chsC and chsA, of Aspergillus nidulans. Curr. Genet. 48:171.

25. Kasuga, T., and Glass, N. L. 2008. Dissecting colony development of Neurospora crassa using mRNA profiling and comparative genomics approaches. Eukaryot. Cell 7:1549-1564.

26. Krappmann, S., Jung, N., Medic, B., Busch, S., Prade, R. A., and Braus, G. H. 2006. The Aspergillus nidulans F-box protein GrrA links SCF activity to meiosis. Mol. Microbiol. 61:76-88.

27. Marcelo, A. V., Karen, Y. M., and Bruce, L. M. 2000. Aspergillus SteA (Sterile12-like) is a homeodomain- $\mathrm{C} 2 \mathrm{H} 2-\mathrm{Zn}+2$ finger transcription factor required for sexual reproduction. Mol. Microbiol. 36:290-301.

28. National Center for Biotechnology Information. 2010. Erysiphales taxonomy browser. http://www.ncbi.nlm.nih.gov/Taxonomy/Browse/ wwwtax.cgi? mode $=$ Info\&id $=5120$.

29. Odenbach, D., Breth, B., Thines, E., Weber, R. W. S., Anke, H., and Foster, A. J. 2007. The transcription factor Con7p is a central regulator of infection-related morphogenesis in the rice blast fungus Magnaporthe grisea. Mol. Microbiol. 64:293-307.

30. Partridge, M., and Murphy, D. J. 2009. Roles of a membrane-bound caleosin and putative peroxygenase in biotic and abiotic stress responses in Arabidopsis. Plant Physiol. Biochem. 47:796.

31. Pathan, A. A. K., Devi, K. U., Vogel, H., and Reineke, A. 2007. Analysis of differential gene expression in the generalist entomopathogenic fungus Beauveria bassiana (Bals.) Vuillemin grown on different insect cuticular extracts and synthetic medium through cDNA-AFLPs. Fungal Genet. Biol. 44:1231-1241.

32. Pearson, R. C., and Gadoury, D. M. 1992. Grapevine powdery mildew. Pages 129-146 in: Plant Diseases of International Importance, Vol. III, Diseases of Fruit Crops. J. Kumar, H. S. Chaube, U. S. Singh, and A. N. Mukhopadhyay, eds. Prentice Hall, NJ.

33. Peeters, T., Versele, M., and Thevelein, J. 2007. Directly from G alpha to protein kinase A: The kelch repeat protein bypass of adenylate cyclase. Trends Biochem. Sci. 32:547-554.
34. Pfaffl, M. W. 2001. A new mathematical model for relative quantification in real-time RT-PCR. Nucleic Acids Res. 29:e45.

35. Polesani, M., Desario, F., Ferrarini, A., Zamboni, A., Pezzotti, M., Kortekamp, A., and Polverari, A. 2008. cDNA-AFLP analysis of plant and pathogen genes expressed in grapevine infected with Plasmopara viticola. BMC Genomics 9:142-155.

36. Shimizu, K., and Keller, N. P. 2001. Genetic involvement of a cAMPdependent protein kinase in a $\mathrm{G}$ protein signaling pathway regulating morphological and chemical translations in Aspergillus nidulans. Genetics 157:591-600.

37. Spanu, P. D., Abbott, J. C., Amselem, J. L., Burgis, T. A., Soanes, D. M., Stüber, K., Ver Loren van Themaat, E., Brown, J. K. M., Butcher, S. A., Gurr, S. J., Lebrun, M.-H., Ridout, C. J., Schulze-Lefert, P., Talbot, N. J., Ahmadinejad, N., Ametz, C., Barton, G. R., Benjdia, M., Bidzinski, P., Bindschedler, L. V., Both, M., Brewer, M. T., Cadle-Davidson, L., CadleDavidson, M. M., Collemare, J., Cramer, R., Francisco, L.-R., Frenkel, O., Godfrey, D., Harriman, J., Hoede, C., King, B. C., Klages, S., Kleemann, J., Knoll, D., Koti, P. S., Kreplak, J., Lu, X., Maekawa, T., Mahanil, S., Milgroom, M. G., Montana, G., Noir, S., O’Connell, R. J., Oberhaensli, S., Parlange, F., Pedersen, C., Quesneville, H., Reinhardt, R., Rott, M., Sacristán, S., Schmidt, S. M., Schön, M., Skamnioti, P., Sommer, H., Stephens, A., Takahara, H., Thordal-Christensen, H., Vigouroux, M., Weßling, R., Wicker, T., and Panstruga, R. 2010. Genome expansion and gene loss in powdery mildew fungi reveal functional tradeoffs in extreme parasitism. Science 330:1543-1546.

38. Timberlake, W. E. 1980. Developmental gene regulation in Aspergillus nidulans. Dev. Biol. 78:497.

39. Tsitsigiannis, D., Zarnowski, R., and Keller, N. 2004. The lipid body protein, PpoA, coordinates sexual and asexual sporulation in Aspergillus nidulans. J. Biol. Chem. 279:11344-11353.

40. Van der Biezen, E. A., Juwana, H., Parker, J., and Jones, J. D. G. 2000. cDNA-AFLP display of Peronospora parasitica genes expressed during infection in Arabidopsis thaliana. Mol. Plant-Microbe Interact. 13:895896.

41. Wakefield, L. M. 2010. Investigations in asexual development in Erysiphe necator: Characterization of factors affecting conidiation and identification of gene sequences associated with developmental changes. Dissertation, Cornell University, Ithaca, NY.

42. Wieser, J, and Adams, T. H. 1995. flbD encodes a Myb-like DNA-binding protein that coordinates initiation of Aspergillus nidulans conidiophore development. Genes Dev. 9:491-502.

43. Wieser, J., Lee, B. N., Fondon, J. W., and Adams, T. H. 1994. Genetic requirements for initiating asexual development in Aspergillus nidulans. Curr. Genet. 27:62-69.

44. Yu, J. H. 2006. Heterotrimeric G protein signaling and RGSs in Aspergillus nidulans. J. Microbiol. 44:145-154. 